\title{
Allosteric Cooperativity in Inhibition of Protein Kinase a Catalytic Subunit
}

\author{
Aleksei Kuznetsov and Jaak Järv*
}

Institute of Chemistry, University of Tartu, 2 Jakobi Str., 51014 Tartu, Estonia

\begin{abstract}
Allosteric cooperativity in inhibition of protein kinase A was studied for the first time kinetically, by using the second-order rate constants of kemptide phosphorylation, measured in the absence and presence of inhibitors, and the effect of cooperativity was characterized in terms of the interaction factor $\gamma$. This kinetic method was evaluated for differently targeted inhibitors $\mathrm{H} 89$ and LRRAALG- $\mathrm{NH}_{2}$, and interaction of these compounds with the free enzyme and the enzyme-substrate complexes was quantified. The inhibitory effect of these compounds was asymmetric relatively ATP and kemptide, and allosteric enhancement of LRRAALG- $\mathrm{NH}_{2}$ binding in the presence of ATP was revealed. This cooperative effect was compared with results of ligand binding studies and the principle "better binding - stronger allostery" was formulated and formalized in terms of a linear-free-energy relationship $\mathrm{p}(\gamma)=\mathrm{C}+S \mathrm{pK}$, where $\mathrm{p}(\gamma)$ stands for the negative $\log$ arithm of the interaction factor and $\mathrm{pK}_{\mathrm{i}}$ characterizes affinity of the free enzyme for the inhibitory peptide, $\mathrm{C}=-2.7$ and $\mathrm{S}=0.9, \mathrm{r}=0.92$.
\end{abstract}

Key Words: Single-subunit allostery, Allosteric cooperativity, Kinetic analysis, Phosphorylation reaction, Inhibition mechanism, cAMP-dependent protein kinase catalytic subunit, Interaction factor.

\section{INTRODUCTION}

Protein kinases (E.C.2.7.1.37) play critical role in various signal transduction pathways and therefore their inhibitors are promising targets for drug development [1]. The reaction catalyzed by these enzymes involves two substrates - the phosphorylatable protein or peptide and ATP as the source of the phosphoryl group. This phosphoryl group is directly transferred between the enzyme-bound substrates [2].

This principle of protein kinase functioning has inspired search for inhibitors, which could be directed into the ATP binding site or into the peptide binding site of these enzymes [3]. In parallel, the concept of bi-substrate analog inhibitors was formulated [4], assuming that potency of inhibitors can be boosted, if they interact simultaneously with both binding sites. In all these studies the design of inhibitors has been guided by structural data for these enzymes. These data are firsthand available for cAMP-dependent protein kinase catalytic subunit (further denoted as PKA), which is the most extensively studied member among protein kinases, and still serves as a "model" for these enzymes.

In the case of PKA the X-ray structures have been determined for the free enzyme [5] and for the enzyme complexes with peptide [6] and low-molecular ATP-analog inhibitor [7]. These studies together with other investigations have revealed that PKA molecule should possess outstanding structural flexibility [8]. Therefore, it can be assumed that inhibitors may form diverse complexes with this enzyme, especially if the presence of two different substrate binding sites is considered. Although this understanding seems to be

\footnotetext{
*Address correspondence to this author at the Institute of Chemistry, University of Tartu, 2 Jakobi Str., 51014 Tartu, Estonia; Tel: +372 7375246; Fax: +372 7375247; E-mail: jaak.jarv@ut.ee
}

appreciated in general, formation of these complexes has not been discussed more thoroughly, recognizing the principle that it is virtually impossible to deduce the molecular mechanism of ligand binding solely from binding data [9].

However, this situation is certainly changing after direct evidence for allosteric cooperativity in PKA molecule, observed by using NMR spectroscopy [10]. These NMR data have clearly demonstrated that substrate and inhibitor may simultaneously bind with the enzyme molecule. Moreover, this study also demonstrated that affinity of PKA for the ATP-site directed inhibitor AMPPNP was increased in the presence of peptide substrate, and vice versa. In other words, it has become clear that effectiveness of binding of a ligand with this enzyme could be influenced by the presence of some other enzyme-bound ligand. However, these ligand binding studies have not revealed whether these allosteric interactions can also be observed the PKA-catalyzed reaction and affect inhibition of the enzyme activity by reversible inhibitors.

In this report we investigated the influence of allosteric interactions between the substrate binding sites and inhibitor binding sites on catalytic activity of PKA, and characterized formation of complexes between the inhibitor molecule and the free enzyme, as well as between the inhibitor and the enzyme-substrate complexes. The particular feature of this kinetic analysis was application of the second-order rate constants, which advantages in analysis of complex enzymatic reactions have been well described [11, 12], but which practical application appeared to be not trivial for the PKA catalyzed bi-substrate reaction.

For evaluation of the proposed method of kinetic analysis we studied interaction of PKA with two differently targeted reversible inhibitors, the isoquinoline derivative H89, 
(N-[2-(p-bromo-cinnamylamino)ethyl]-5-isoquinolinesulfonamide), designed to block the ATP binding site of PKA, and the non-phosphorylatable analog of kemptide, LRRAALG$\mathrm{NH}_{2}$. This study revealed that the influence of these inhibitors on interaction of PKA with ATP and kemptide was clearly asymmetric in terms of the inhibition mechanism, and included allosteric cooperativity, which significantly affected the enzyme-inhibitor interactions. Moreover, in this study kinetic evidence for cooperative effect of ATP on binding of peptide inhibitor was obtained for the first time. This effect of cooperativity in PKA kinetics was comparable with similar effects observed in binding studies with other peptide inhibitors and the principle "better binding - stronger allostery" was formulated and formalized in terms a linearfree-energy relationship.

\section{MATERIALS AND METHODS}

\section{Kinetic Formalism}

The following analysis was based on understanding that the ternary complex between ATP, peptide and the enzyme, denoted as A, B and E (see Fig. (1)), should be formed before the phosphoryl transfer step [2, 13]. Secondly, it was suggested that the inhibitor I may bind with the free enzyme (E) and with the enzyme-substrate complexes EA and EB, as shown in Fig. (1). Finally, the option of partial enzyme inhibition was considered in this reaction scheme by introducing additional reaction path proceeding from the complex EABI.

For discrimination between the complete and partial inhibition mechanisms the reaction rate $v s[\mathrm{I}]$ plot can be analyzed at constant concentration of substrates $A$ and $B$. In the case of the complete inhibition mechanism the rate equation (1) simplifies, as $\frac{\delta}{\beta \gamma \mathrm{K}_{\mathrm{i}}}=0$, and the reaction rate should go down to zero at high inhibitor concentration. This means that linear plot should be observed in coordinates $1 / \mathrm{v}$ and [I]. For the partial inhibition mechanism, however, the enzyme activity should level off at high inhibitor concentration, where the reaction path via EABI becomes effective. This, in turn, can be easily used for diagnostics of the reaction mechanism, as the partial inhibition mechanism causes non-linear $1 / \mathrm{v}$ vs [I] plot.

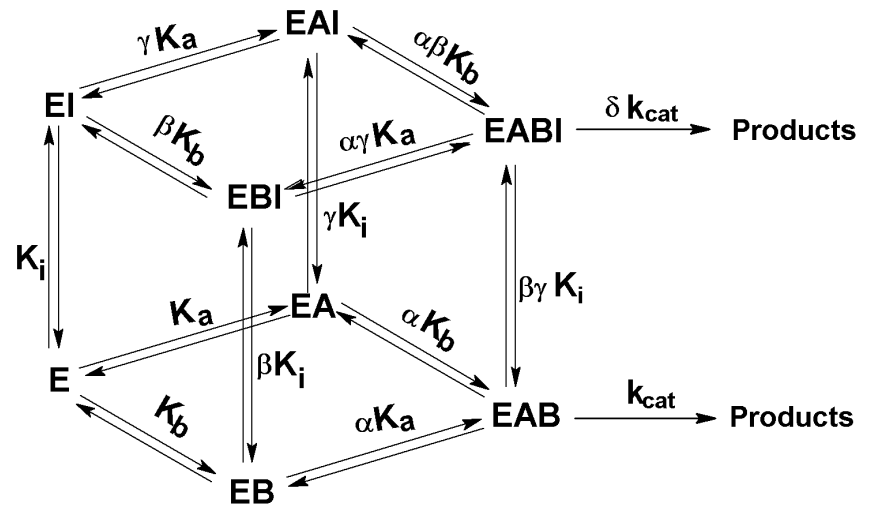

Fig. (1). Kinetic scheme for inhibition of bi-substrate enzyme reaction by a reversible inhibitor I.

$$
\frac{\mathrm{v}}{\left[\mathrm{E}_{0}\right]}=\frac{\mathrm{k}_{\mathrm{cat}}\left(\frac{[\mathrm{A}][\mathrm{B}]}{\alpha \mathrm{K}_{\mathrm{a}} \mathrm{K}_{\mathrm{b}}}+\frac{\delta[\mathrm{A}][\mathrm{B}][\mathrm{I}]}{\alpha \beta \gamma \mathrm{K}_{\mathrm{a}} \mathrm{K}_{\mathrm{b}} \mathrm{K}_{\mathrm{i}}}\right)}{1+\frac{[\mathrm{A}]}{\mathrm{K}_{\mathrm{a}}}+\frac{[\mathrm{B}]}{\mathrm{K}_{\mathrm{b}}}+\frac{[\mathrm{I}]}{\mathrm{K}_{\mathrm{i}}}+\frac{[\mathrm{A}][\mathrm{B}]}{\alpha \mathrm{K}_{\mathrm{a}} \mathrm{K}_{\mathrm{b}}}+\frac{[\mathrm{A}][\mathrm{I}]}{\gamma \mathrm{K}_{\mathrm{a}} \mathrm{K}_{\mathrm{i}}}+\frac{[\mathrm{B}][\mathrm{I}]}{\beta \mathrm{K}_{\mathrm{b}} \mathrm{K}_{\mathrm{i}}}+\frac{[\mathrm{A}][\mathrm{B}][\mathrm{I}]}{\alpha \beta \gamma \mathrm{K}_{\mathrm{a}} \mathrm{K}_{\mathrm{b}} \mathrm{K}_{\mathrm{i}}}}
$$

For practical use we customized the rate equation (1) for step-by-step data processing [14]. Briefly, Eq. (1) was rearranged for two options, considering varied [A] at fixed [B] and $[\mathrm{I}]$, and varied $[\mathrm{B}]$ at fixed $[\mathrm{A}]$ and $[\mathrm{I}]$. From these datasets the second-order rate constants $\mathrm{k}_{\mathrm{II}}$ were obtained (see Eqs. (2) and (3)), and were further used for calculation of complex parameters $\mathrm{X}_{\mathrm{i}}, \mathrm{Y}_{\mathrm{i}}, \mathrm{Q}_{\mathrm{i}}$ and $\mathrm{U}_{\mathrm{i}}$ as shown below:

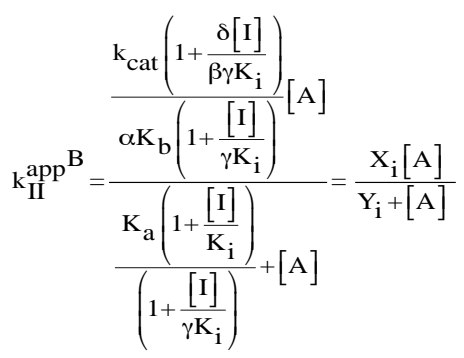

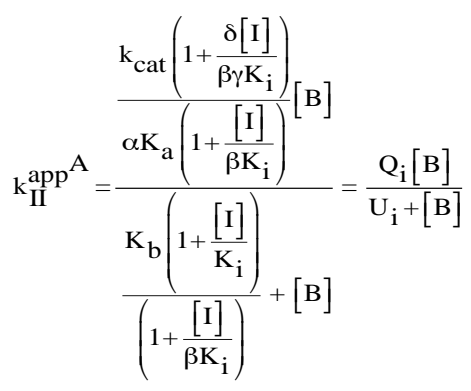
ing:

The parameters $X_{i}, Y_{i}, Q_{i}$ and $U_{i}$ had the following mean-

$$
\mathrm{X}_{\mathrm{i}}=\frac{\frac{\mathrm{k}_{\mathrm{cat}} \gamma \mathrm{K}_{\mathrm{i}}}{\alpha \mathrm{K}_{\mathrm{b}}}\left(1+\frac{\delta[\mathrm{I}]}{\beta \gamma \mathrm{K}_{\mathrm{i}}}\right)}{\gamma \mathrm{K}_{\mathrm{i}}+[\mathrm{I}]},
$$

$$
\mathrm{Y}_{\mathrm{i}}=\frac{\mathrm{K}_{\mathrm{a}} \gamma \mathrm{K}_{\mathrm{i}}\left(1+\frac{[\mathrm{I}]}{\mathrm{K}_{\mathrm{i}}}\right)}{\gamma \mathrm{K}_{\mathrm{i}}+[\mathrm{I}]},
$$

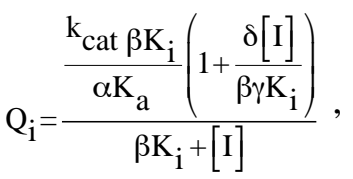

$$
\mathrm{U}_{\mathrm{i}}=\frac{\mathrm{K}_{\mathrm{b}} \beta \mathrm{K}_{\mathrm{i}}\left(1+\frac{[\mathrm{I}]}{\mathrm{K}_{\mathrm{i}}}\right)}{\beta \mathrm{K}_{\mathrm{i}}+[\mathrm{I}]} .
$$


In general, the hyperbolic plots of $\mathrm{X}_{\mathrm{i}}$ and $\mathrm{Q}_{\mathrm{i}} v s[\mathrm{I}]$ can be used for calculation of the inhibition constants $\beta \mathrm{K}_{\mathrm{i}}$ and $\gamma \mathrm{K}_{\mathrm{i}}$, while the $\mathrm{K}_{\mathrm{i}}$ values can be calculated from the $\mathrm{X}_{\mathrm{i}} / \mathrm{Y}_{\mathrm{i}}$ vs [I] and $\mathrm{Q}_{\mathrm{i}} / \mathrm{U}_{\mathrm{i}} v s[\mathrm{I}]$ plots. For the complete inhibition mechanism, however, Eqs. (4) and (6) were simplified, as $\frac{\delta}{\beta \gamma \mathrm{K}_{\mathrm{i}}}=0$,

and the $\mathrm{K}_{\mathrm{i}}$ values were calculated from the linear plots of $\mathrm{Y}_{\mathrm{i}} / \mathrm{X}_{\mathrm{i}} v s[\mathrm{I}]$ and $\mathrm{U}_{\mathrm{i}} / \mathrm{Q}_{\mathrm{i}}$ vs [I] plots, as shown below:

$$
\begin{aligned}
& \frac{\mathrm{Y}_{\mathrm{i}}}{\mathrm{X}_{\mathrm{i}}}=\frac{\alpha \mathrm{K}_{\mathrm{b}} \mathrm{K}_{\mathrm{a}}}{\mathrm{k}_{\text {cat }}}+\frac{\alpha \mathrm{K}_{\mathrm{b}} \mathrm{K}_{\mathrm{a}}}{\mathrm{K}_{\mathrm{i}} \mathrm{k}_{\text {cat }}}[\mathrm{I}] \\
& \frac{\mathrm{Q}_{\mathrm{i}}}{\mathrm{U}_{\mathrm{i}}}=\frac{\alpha \mathrm{K}_{\mathrm{a}} \mathrm{K}_{\mathrm{b}}}{\mathrm{k}_{\text {cat }}}+\frac{\alpha \mathrm{K}_{\mathrm{a}} \mathrm{K}_{\mathrm{b}}}{\mathrm{K}_{\mathrm{i}} \mathrm{k}_{\text {cat }}}[\mathrm{I}]
\end{aligned}
$$

\section{Chemicals}

$\gamma-\left[{ }^{32} \mathrm{P}\right] \mathrm{ATP}$ was obtained from Amersham (UK). Peptides LRRASLG (kemptide) and LRRAALG- $\mathrm{NH}_{2}$ (Ala-kemptide amide) were synthesized in a stepwise manner on a 0.1 mmol scale using the Applied Biosystem peptide synthesizer (USA) as described elsewhere [15]. Inhibitor H89 (N-[2-((pbromocinnamyl)amino)-ethyl]-5-isoquinolinesulfon-amide, 2 $\mathrm{HCl}$ ), TRIS/HCl, ATP, BSA and $\mathrm{H}_{3} \mathrm{PO}_{4}$ were obtained from Sigma-Aldrich (USA). Phosphocellulose paper P81 was acquired from Whatman (UK). $\mathrm{MgCl}_{2}$ was purchased from Acros (Germany). The catalytic subunit $\mathrm{C}_{\text {alpha }}$ of mouse cAMP-dependent protein kinase (PKA), recombinantly expressed in E.coli, $30 \mathrm{U} / \mathrm{mg}, 0.1 \mathrm{mg} / \mathrm{ml}$, lot 040916, was obtained from Biaffin $\mathrm{GmbH} \&$ Co KG (Germany).

\section{Kinetic Measurements}

Initial rate of kemptide phosphorylation was measured at $30^{\circ} \mathrm{C}$ as described in $[16,17]$. Briefly, the reaction mixture (final volume $100 \mu \mathrm{l}, 50 \mathrm{mM}$ TRIS/HCl, $\mathrm{pH}$ 7.5) contained kemptide at various concentrations from 5 to $200 \mu \mathrm{M}, \gamma$ $\left[{ }^{32} \mathrm{P}\right] \mathrm{ATP}$ at various concentrations from 5 to $400 \mu \mathrm{M}, 10$ $\mathrm{mM}$ of $\mathrm{MgCl}_{2}$ and $0.10-10 \mu \mathrm{g} / \mathrm{ml}$ of the enzyme. In the inhibition assays, the reaction mixture contained also 25 and 50 $\mathrm{nM}$ of $\mathrm{H} 89$ and 100 and $200 \mu \mathrm{M}$ of the kemptide Ala analog LRRAALG-NH $\mathrm{N}_{2}$. The stock solution of PKA was diluted into $50 \mathrm{mM}$ TRIS/HCl buffer (pH 7.5) containing $1 \mathrm{mg} / \mathrm{ml}$ $\mathrm{BSA}$, and $15 \mu \mathrm{l}$ of this solution was added into the reaction mixture to initiate the phosphorylation reaction. At different time moments $10 \mu \mathrm{l}$ aliquots were removed from the reaction mixture and spotted onto the pieces of phosphocellulose paper, which were subsequently immersed into the ice-cold 75 $\mathrm{mM}$ phosphoric acid to stop the reaction. The phosphocellulose papers were then washed four times with cold $75 \mathrm{mM}$ $\mathrm{H}_{3} \mathrm{PO}_{4}\left(10\right.$ min each time) to remove excess $\gamma-\left[{ }^{32} \mathrm{P}\right]$ ATP and dried at $120^{\circ} \mathrm{C}$ for $25 \mathrm{~min}$. The radioactivity bound onto the paper was measured as Cherenkov radiation using a Beckman LS 7500 scintillation counter. The values of the initial rate of the phosphorylation reaction $\left(\mathrm{v}_{\mathrm{o}}\right)$ were calculated from the slopes of the product concentration $v$ s time plots.

\section{Data Analysis}

For data processing the algorithm described above was used. Velocities of substrate phosphorylation were measured at different ATP $(5-400 \mu \mathrm{M})$ and kemptide $(5-200 \mu \mathrm{M})$ concentrations in the absence and in the presence of inhibitors H89 $(0.025$ and $0.05 \mu \mathrm{M})$ or LRRAALG-NH 2 (100 and $200 \mu \mathrm{M})$. The kinetic data were analyzed in subsets as described above.

\section{Calculations}

Calculations and statistical analysis of the data were made using the GraphPad Prism (version 4.0, GraphPad Software Inc., USA) and SigmaPlot (version 8.0, SPSS Inc., USA) software packages. The results reported were listed with standard errors.

\section{RESULTS}

\section{Complete Inhibition of PKA by H89 and LRRAALG- $\mathrm{NH}_{2}$}

The arrays of the reaction rate data (approx 400 datapoints each) were obtained at various concentrations of both substrates and in the presence and absence of H89 and LRRAALG-NH 2 . These data were illustrated as threedimensional plots in Fig. (2), where colors change from blue to red to demonstrate the increase in reaction rate. It can be seen that the phosphorylation rate decreased in the presence
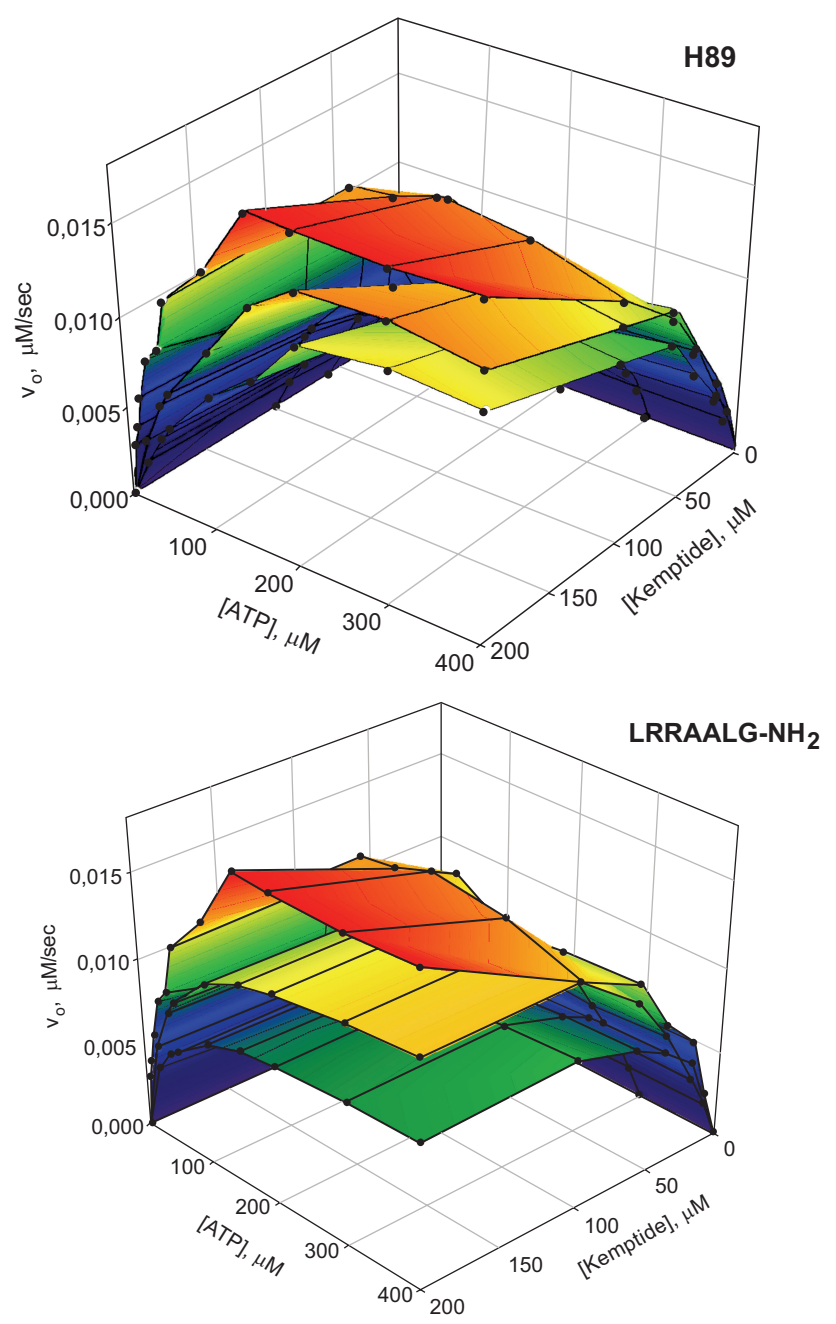

Fig. (2). Inhibition of the PKA-catalyzed kemptide phosphorylation in the presence of $\mathrm{H} 89$ (upper panel, inhibitor concentrations from bottom: $0.05 \mu \mathrm{M}, 0.025 \mu \mathrm{M}$ and $0 \mu \mathrm{M}$ ), and in the presence of peptide inhibitor LRRAALG- $\mathrm{NH}_{2}$ (lower panel, inhibitor concentrations from bottom: $200 \mu \mathrm{M}, 100 \mu \mathrm{M}$ and $0 \mu \mathrm{M})$. 
of both inhibitors, and the inhibition effect was dosedependent, as illustrated by the conventional inhibition curves in Fig. (3). The latter data provided also evidence for the complete inhibition mechanism, as the $1 / \mathrm{v}$ vs [I] plots were linear for both compounds, as shown in intercepts of Fig. (3).
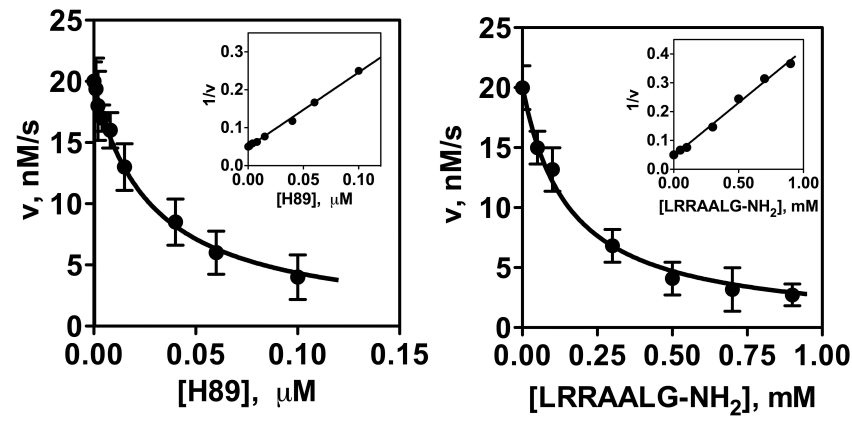

Fig. (3). Inhibition of PKA by H89 (left) and peptide inhibitor LRRAALG-NH $\mathrm{N}_{2}$ (right), studied in the presence of $100 \mu \mathrm{M}$ ATP and $100 \mu \mathrm{M}$ kemptide concentrations.

The plots shown in Fig. (3) were analyzed as conventional inhibition curves and the $\mathrm{IC}_{50}$ values $0.031 \pm 0.002$ $\mu \mathrm{M}$ and $152 \pm 27 \mu \mathrm{M}$ were calculated from these data for H89 and LRRAALG-NH2 at $100 \mu \mathrm{M}$ ATP, respectively. This inhibitory effect of $\mathrm{H} 89$ was close to the $\mathrm{K}_{\mathrm{i}}$ value 0.048 $\pm 0.008 \mu \mathrm{M}$, determined for bovine heart PKA in [18]. Although no inhibition data were found for peptide LRRAALG-NH 2 , the $\mathrm{IC}_{50}$ value for this compound was close to the $K_{i}=376 \mu \mathrm{M}$ for peptide LRRAALG [19], and remained in the same range with similar data, reported for short peptides with the C-terminal amide group [20]. Certainly, these results could not give hint for the presence of allosteric cooperativity, as constant concentration of both substrates was used.

\section{Inhibition Constants}

From the arrays of the kinetic data shown in Fig. (2) the second order rate constants and further the complex parameters $\mathrm{X}_{\mathrm{i}}, \mathrm{Y}_{\mathrm{i}}, \mathrm{Q}_{\mathrm{i}}$ and $\mathrm{Y}_{\mathrm{i}}$ were calculated and used for determination of the $\mathrm{K}_{\mathrm{i}}, \beta \mathrm{K}_{\mathrm{i}}$ and $\gamma \mathrm{K}_{\mathrm{i}}$ values as described above. The results of this analysis were listed in Table $\mathbf{1 .}$

Table 1. Interaction of inhibitors $\mathrm{H89}$ and LRRAALG-NH with the free PKA $\left(K_{i}\right)$, with the Enzyme-ATP Complex $\left(\beta K_{i}\right)$, with the Enzyme-Kemptide Complex $\left(\gamma K_{i}\right)$ and with the Enzyme-ATP-Kemptide Ternary Complex $\left(\beta \gamma K_{i}\right)$. The Meaning of the Listed Parameters is Specified by the Reaction Scheme in Fig. (1)

\begin{tabular}{|c|c|c|}
\hline \multirow{2}{*}{ Parameter } & \multicolumn{2}{|c|}{ Inhibitor } \\
\cline { 2 - 3 } & $\mathbf{H ~ 8 9}$ & LRRAALG-NH2 \\
\hline \hline $\mathrm{K}_{\mathrm{i}}, \mu \mathrm{M}$ & $0,009 \pm 0,002$ & $161 \pm 32$ \\
\hline$\beta \mathrm{K}_{\mathrm{i}}, \mu \mathrm{M}$ & $0,016 \pm 0,003$ & $77 \pm 18$ \\
\hline$\gamma \mathrm{K}_{\mathrm{i}}, \mu \mathrm{M}$ & $0,08 \pm 0,01$ & $45 \pm 10$ \\
\hline$\beta \gamma \mathrm{K}_{\mathrm{i}}, \mu \mathrm{M}$ & Not determined & $39 \pm 20$ \\
\hline$\beta$ & 1.8 & 0.5 \\
\hline$\gamma$ & 8.9 & 0.3 \\
\hline
\end{tabular}

Importantly, the $\mathrm{X}_{\mathrm{i}} / \mathrm{Y}_{\mathrm{i}}$ vs $[\mathrm{I}]$ and $\mathrm{Q}_{\mathrm{i}} / \mathrm{U}_{\mathrm{i}}$ vs $[\mathrm{I}]$ plots coincided well for both inhibitors, as seen in Fig. (4). As experimental data used for calculation of the $\mathrm{Y}_{\mathrm{i}} / \mathrm{X}_{\mathrm{i}}$ and $\mathrm{U}_{\mathrm{i}} / \mathrm{Q}_{\mathrm{i}}$ values were obtained from different kinetic experiments, this result could be taken as validation of the kinetic analysis made.
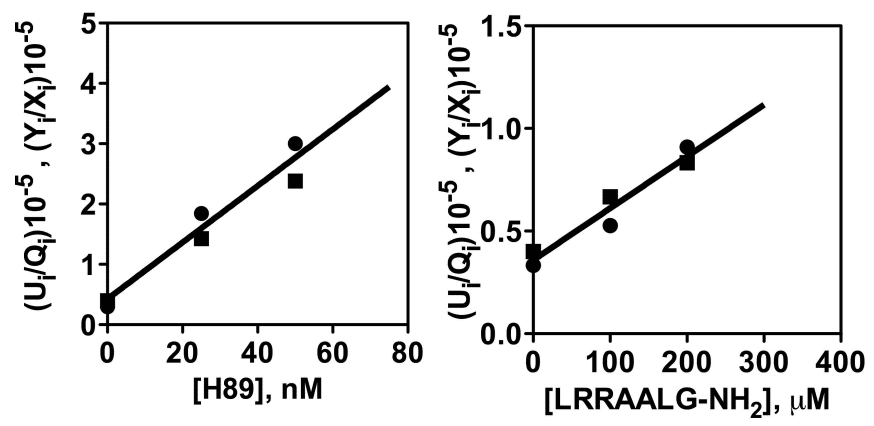

Fig. (4). Calculation of the $K_{i}$ values for PKA interaction with $\mathrm{H} 89$ (left) and LRRAALG-NH ${ }_{2}$ (right) from the $\mathrm{Y}_{\mathrm{i}} / \mathrm{X}_{\mathrm{i}}$ plot (匹) and from $\mathrm{U}_{\mathrm{i}} / \mathrm{Q}_{\mathrm{i}}$ plot (•), as described by Eqs. (8) and (9).

\section{Allosteric Cooperativity in Inhibition of PKA Catalysis}

The constants $\mathrm{K}_{\mathrm{i}}, \beta \mathrm{K}_{\mathrm{i}}$ and $\gamma \mathrm{K}_{\mathrm{i}}$ (Table 1) were used for calculation of coefficients $\beta$ and $\gamma$ for both inhibitors studied. These parameters were defined as interaction factors in Fig. (1), and they compare effectiveness of inhibitor binding with the free enzyme E and the EA complex $(\beta)$, or with the free enzyme E and the EB complex $(\gamma)$, respectively [14]. Consequently, these values quantitatively characterize allosteric interactions which govern binding properties of these sites.

We have also introduced separate entry for the constant $\beta \gamma \mathrm{K}_{\mathrm{i}}$ in Table 1. This parameter, quantifies the formation of the ternary complex EABI, can be determined directly from experimental data, as shown in [16], or calculated indirectly by combining the $K_{i}, \beta$ and $\gamma$ values. In this study we were able to detect experimentally the formation of this quaternary complex in the case of LRRAALG- $\mathrm{NH}_{2}$ (see Table 1), while similar value can be calculated from $\mathrm{K}_{\mathrm{i}}, \beta$ and $\gamma$ for this peptide. Consequently, the formation of the quaternary complex EABI was relevant for interaction of LRRAALG- $\mathrm{NH}_{2}$ with PKA. In the case of H89, however, the value of $\beta \gamma \mathrm{K}_{\mathrm{i}}$ could not be reliably determined, but was only estimated to be approx $0.14 \mu \mathrm{M}$ by combining the $\mathrm{K}_{\mathrm{i}}, \beta$ and $\gamma$ values in Table 1. Indeed, at so high concentration of $\mathrm{H} 89$ the rate of peptide phosphorylation cannot be monitored.

\section{DISCUSSION}

The results of the present kinetic analysis revealed that allosteric cooperative interactions between substrate and inhibitor binding sites may affect catalytic properties of PKA, while in all previous studies the allosteric effect has been studied by using ligand binding assays. Two wellknown reversible inhibitors were selected for this kinetic analysis, proceeding from the fact that these compounds bind at distinct binding sites of PKA. Therefore it was not surprising that the influence of these ligands on ATP and kemptide binding with the enzyme was asymmetric and was differently governed by allostery, quantified by the $\beta$ and $\gamma$ values in Table $\mathbf{1 .}$

It is notable that binding of ATP with PKA was significantly hindered by H89 $(\gamma=8.9)$, in agreement with the 
ATP-site directed binding mode of this inhibitor [7]. However, this inhibitor also blocked kemptide binding $(\beta=1.8)$. Thus H89 revealed at least some properties of bi-substrate inhibitors, which are specially designed to interact simultaneously with the ATP and peptide binding sites, and therefore should affect binding of both substrates. For a bisubstrate inhibitor $\operatorname{AdcAhxArg}_{6} \gamma=12$ and $\beta=3$ [17]. Consequently, the borderline between the mono-substrate and bisubstrate inhibitors seems to be not very strict, or perhaps even not existing, at least as far as the kinetic mechanism and allosteric cooperativity of PKA is considered.

The situation observed with LRRAALG- $\mathrm{NH}_{2}$ was rather different, as the constants $\beta \mathrm{K}_{\mathrm{i}}$ and $\gamma \mathrm{K}_{\mathrm{i}}$ were smaller than the $\mathrm{K}_{\mathrm{i}}$ value (Table 1). Thus the binding effectiveness of this compound increased in the presence of ATP $(\beta=0.3)$ as well as kemptide $(\gamma=0.5)$, pointing to positive cooperativity between the appropriate binding sites, which should simultaneously accommodate the peptide inhibitor, ATP and kemptide. Indeed, in this case the formation of the quaternary complex EABI was detected experimentally and the $\beta \gamma \mathrm{K}_{\mathrm{i}}$ value $39 \mu \mathrm{M}$ was determined (Table 1). This seems to be an intriguing situation, as the substrate and the peptide inhibitor have rather similar structure and it would be natural to assume that they are similarly recognized by the enzyme. On the other hand, however, the possibility of simultaneous interaction of protein kinases with several peptides or with several parts of the same protein may provide additional possibility for fine regulation of these enzymes and thus might have biological relevance.

Interactions between different binding sites on PKA have been described also in other studies, for instance by comparing inhibitory peptide binding with the free enzyme and with the enzyme-ATP complex. Following the reaction scheme shown in Fig. (1), the appropriate dissociation constants can be denoted as $\mathrm{K}_{\mathrm{i}}$ and $\gamma \mathrm{K}_{\mathrm{i}}$, respectively, where $\gamma$ stands for the interaction factor, which quantifies the cooperative effect of ATP on binding of peptide inhibitors. Most explicitly this cooperative effect has been characterized for interaction of the catalytic and regulatory subunits of protein kinase A, where the dissociation constant $125 \mathrm{nM}$ for the free enzyme [21] decreased to $40 \mathrm{pM}$ in the presence of ATP [22], yielding $\gamma=0.0003$. Significant increase in affinity of PKA in the presence of ATP has also been observed for the heat-stable peptide inhibitor (PKI), characterized by the dissociation constants $2.3 \mu \mathrm{M}$ [21] and $2 \mathrm{nM}[23,24]$, respectively. In this case $\gamma=0.0009$. These cooperative effects are very large, if compared with the $\gamma$ value 0.3, observed for LRRAALG$\mathrm{NH}_{2}$ in this kinetic study. On the other hand, however, affinity of PKA for the inhibitory peptides is also very high and therefore we suggested that the cooperative effect may depend on binding effectiveness of the peptide, following the principle "better binding - stronger allostery". Indeed, this interrelationship was observed and formalized in terms of a linear-free-energy relationship, as shown in Fig. (5):

$$
\mathbf{p}(\gamma)=\mathrm{C}+S \mathbf{p K} \mathbf{K}_{\mathrm{i}}
$$

In this equation the negative logarithm of the interaction factor $\gamma$, denoted as $\mathrm{p}(\gamma)$, was plotted against the $\mathrm{pK}_{\mathrm{i}}$ values, characterizing binding of inhibitory peptides with the free enzyme. The constant $C$ stands for intercept and $S$ for the slope of the linear plot (Fig. 5).

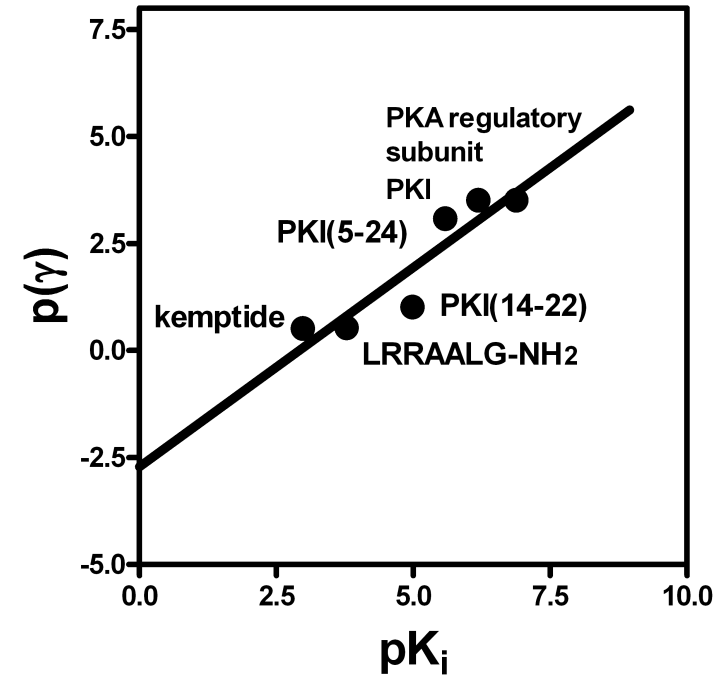

Fig. (5). Linear-free-energy relationship between the negative logarithms of the interaction factor $\gamma$, characterizing allosteric effect of ATP on binding of inhibitory peptides with PKA, upon the binding effectiveness of these peptides with the free enzyme $\left(\mathrm{pK}_{\mathrm{i}}\right)$. Data for PKA regulatory subunit, PKI and its fragments PKI(5-24) and PKI(14-22) were compiled from Refs [21-25], data for kemptide binding were taken from Ref (10), data for LRRAALG-NH ${ }_{2}$ were taken from Table 1.

This linear-free-energy relationship was extended by including binding data for PKI fragments, namely PKI(5-24), and PKI(14-22), for which the $p(\gamma)$ and $\mathrm{pK}_{\mathrm{i}}$ values were calculated from ATP binding data, determined in the presence of these peptide inhibitors by using the acrylodan-modified enzyme [25]. It can be seen in Fig. (5) that all these data fitted well with this linear relationship and thus agree with the principle "better binding - stronger allostery", linking binding effectiveness of peptide inhibitors with the magnitude of the cooperative effect induced by ATP binding.

The linear-free-energy relationship shown in Fig. (5) was characterized by the following parameters: $C=-2.7 \pm 1.0, S$ $=0.93 \pm 0.20, r=0.92$. As seen, this line has intercept with the $\mathrm{x}$-axis at the $\mathrm{pK}_{\mathrm{i}}$ value 2.9 . Formally this means that below this $\mathrm{pK}_{\mathrm{i}}$ value $\beta>1$, and ATP binding should hinder binding of poorly binding peptides. In other words, the positive allosteric cooperativity should convert into negative allosteric cooperativity, if binding effectiveness of peptide inhibitors decreases below some limit. This phenomenon may play significant role in fine tuning of ligand recognition by PKA under physiological conditions.

Secondly, the dependence of the allosteric effect upon ligand binding effectiveness and structure seems to be a continuous function. Therefore the allostery of PKA can hardly be explained by the presence of enumerate and fixed conformational states of the protein, shifted by ligand binding and governing affinity of the enzyme. More likely, the allosteric phenomena observed reflect some continuous change in PKA conformation, which influences ligand binding and can be observed as effect of allosteric cooperativity. Therefore it is not surprising that more efficient ligand binding results in more extensive conformational change and triggers off more significant allosteric effect, as seen from the LFE relationship in Fig. (5). From this point of view PKA seems to be an interesting example of monomeric enzyme, which activity is regulated by allosteric cooperativity in this specific way. 
Finally, it is important to emphasize that in the case of PKA inhibition, the binding effectiveness of inhibitors is not governed only by structure of these molecules, but also depends on properties of substrates present. Practically this means that the design of efficient PKA inhibitors should be targeted towards regulatory phosphorylation reaction of certain substrate, rather than be guided by data on ligand binding effectiveness. This, in turn, may explain the modest success of theoretical drug design methods in the case of protein kinases in general. Therefore the idea about cooperative interactions between different binding sites of PKA, and the possibility of kinetic investigation into the role of these allosteric effects in substrate phosphorylation reaction, may support future developments in the field of inhibitor design for protein kinases.

\section{ABBREVIATIONS}

$\begin{array}{lll}\text { PKA } & = & \begin{array}{l}\text { Catalytic subunit of cAMP-dependent } \\ \text { protein kinase }(\text { E.C.2.7.1.37) }\end{array} \\ \text { H89 } & = & \begin{array}{l}\text { N-[2-(p-bromocinnamy-lamino)ethyl]- } \\ 5 \text {-isoquinolinesulfon-amide })\end{array} \\ \text { kemptide } & =\quad \text { LRRASLG } \\ \text { AMPPNP } & =\text { Adenosine 5'-( } \beta, \gamma \text {-imido)triphosphate } \\ \text { ATP } & = & \text { Adenosine 5'-triphosphate } \\ \text { cAMP } & = & 3 ' 5^{\prime} \text {-Cyclic adenosine monophosphate } \\ \text { BSA } & = & \text { Bovine serum albumin } \\ \text { PKI } & = & \text { Heat-stable peptide inhibitor of PKA }\end{array}$

\section{ACKNOWLEDGEMENTS}

This investigation was supported by the Estonian Ministry of Education and Research Grant SF0180064s8.

\section{REFERENCES}

[1] Glazer RI. The protein kinase ABC's of signal transduction as targets for drug development. Curr Pharm Des 1998; 4: 277-90.

[2] Ho M, Bramson HN, Hansen DE, Knowles JR, Kaiser ET. Stereochemical course of the phosphor group transfer catalyzed by cAMP-dependent protein kinase. J Am Chem Soc 1988; 110: 26801.

[3] Akritopoulou-Zanze I. The identification of new protein kinase inhibitors as targets in modern drug discovery. I Drugs 2006; 9: 481-7.

[4] Ricouart A, Gesquiere JC, Tartar A, Sergheraert C. Design of potent protein kinase inhibitors using the bisubstrate approach. J Med Chem 1991; 34: 73-8.

[5] Knighton DR, Zheng J, Ten Eyck LF, et al. Crystal structure of the catalytic subunit of cyclic adenosine monophosphate-dependent protein kinase. Science 1991; 253: 407-14.

[6] Knighton DR, Zheng JH, Ten Eyck LF, Xuong NH, Taylor SS, Sowadski JM. Structure of a peptide inhibitor bound to the catalytic subunit of cyclic adenosine monophosphate-dependent protein kinase. Science 1991; 253: 414-20.
[7] Engh RA, Girod A, Kinzel V, Huber R, Bossemeyer D. Crystal structures of catalytic subunit of cAMP-dependent protein kinase in complex with isoquinolinesulfonyl protein kinase inhibitors $\mathrm{H}$, H8, and H89. Structural implications for selectivity. J Biol Chem 1996; 271: 26157-64.

[8] Taylor SS, Yang J, Wu J, Haste NM, Radzio-Andzelm E, Anand G. PKA: a portrait of protein kinase dynamics. Biochim Biophys Acta 2004; 1697: 259-69.

[9] Henis YI, Alexander Levitzki A. Ligand Competition Curves as a Diagnostic Tool for Delineating the Nature of Site-Site Interactions: Theory. Eur J Biochem 1979; 102: 449-66.

[10] Masterson LR, Mascioni A, Traaseth NJ, Taylor SS, Veglia G. Allosteric cooperativity in protein kinase A. Proc Natl Acad Sci USA 2008; 105: 506-11.

[11] Koshland DE. The application and usefulness of the ratio $\mathrm{k}(\mathrm{cat}) / \mathrm{K}(\mathrm{M})$. Bioorg Chem 2002; 30: 211-3.

[12] Eisenthal R, Danson MJ, Hough DW. Catalytic efficiency and kcat/KM: a useful comparator? Trends Biotechnol 2007; 25: 247-9.

[13] Lew J, Taylor SS, Adams JA. Identification of a partially ratedetermining step in the catalytic mechanism of cAMP-dependent protein kinase: a transient kinetic study using stopped-flow fluorescence spectroscopy. Biochemistry 1997; 36: 6717-24.

[14] Segel IH. Enzyme kinetics. Behavior and analysis of rapid equilibrium and steady-state enzyme systems. New York, London, Sydney, Toronto: John Wiley \& Sons 1975; pp. 293-99.

[15] Kuznetsov A, Oskolkov N, Hansen M, Järv J. Steady-state kinetic analysis of protein kinase A interaction with peptide and ATP. Proc Estonian Acad Sci Chem 2003; 52: 165-77.

[16] Roskoski RJr. Assays of protein kinase. Methods Enzymol 1983; 99: 3-6.

[17] Kuznetsov A, Uri A, Raidaru G, Järv J. Kinetic analysis of inhibition of cAMP-dependent protein kinase catalytic subunit by the peptide-nucleoside conjugate AdcAhxArg6. Bioorg Chem 2004; 32: 527-35.

[18] Hidaka H, Watanabe M, Kobayashi R. Properties and use of Hseries compounds as protein kinase inhibitors. Methods Enzymol 1991; 201: 328-39.

[19] Glass DB. Differential responses of cyclic GMP-dependent and cyclic AMP-dependent protein kinases to synthetic peptide inhibitors. Biochem J 1983; 213: 159-64.

[20] Cheng HC, Kemp BE, Pearson RB, et al. A potent synthetic peptide inhibitor of the cAMP-dependent protein kinase. J Biol Chem 1986; 261: 989-92.

[21] Herberg FW, Taylor SS. Physiological inhibitors of the catalytic subunit of cAMP-dependent protein kinase: effect of MgATP on protein-protein interactions. Biochemistry 1993; 32: 14015-22.

[22] Herberg FW, Dostmann WR, Zorn M, Davis SJ, Taylor SS. Crosstalk between domains in the regulatory subunit of cAMPdependent protein kinase: influence of amino terminus on cAMP binding and holoenzyme formation. Biochemistry 1994; 33: 748594.

[23] Demaille JG, Peters KA, Fischer EH. Isolation and properties of the rabbit skeletal muscle protein inhibitor of adenosine 3',5'monophosphate dependent protein kinases. Biochemistry 1977; 16: 3080-6.

[24] Feramisco JR, Krebs EG. Inhibition of cyclic AMP-dependent protein kinase by analogues of a synthetic peptide substrate. J Biol Chem 1978; 253: 8968-71.

[25] Lew J, Coruh N, Tsigelny I, Garrod S, Taylor SS. Synergistic binding of nucleotides and inhibitors to cAMP-dependent protein kinase examined by acrylodan fluorescence spectroscopy. J Biol Chem 1997; 272: 1507-13.

(C) Kuznetsov and Järv; Licensee Bentham Open.

This is an open access article distributed under the terms of the Creative Commons Attribution License (http://creativecommons.org/licenses/by/2.5/), which permits unrestrictive use, distribution, and reproduction in any medium, provided the original work is properly cited. 